\title{
Resources and Readiness: the graduate capital perspective as a new approach to graduate employability
}

\section{Michael Tomlinson, Hazel McCafferty, Helen Fuge, Kathryn Wood}

\section{This article presents a new perspective on} graduate employability based on a graduate capital model which emphasises the significant role that various forms of capital can play in the development of their employability. We define these forms of capital here as key resources that potentially empower graduates and equip them for managing the transition from $\mathrm{HE}$ to the labour market. The article explores the various forms of capital which make up the model and illustrates why and how these are applicable for graduates. We finally consider the practical potential of this approach and how practitioners might be able to work with it in order to help students and graduates during and beyond higher education.

\section{Introduction}

The role that universities can play in enhancing graduates' post-university employment outcomes continues to be of great interest to multiple stakeholders - policy-makers, employers, careers practitioners, programme designers, senior managers and, not least, students and graduates themselves. The need to work creatively towards effective employability approaches, which are also conceptuallyinformed, has perhaps never been greater. In the English HE context, recent market-driven reform proposals have made stronger links between graduate outcomes and the quality of their institutional provision (DBIS, 2016), bringing new challenges for the practitioner community.
This article presents an alternative approach to understanding graduate employability, one which departs from the dominant skills and attributes approach so common in much thinking and provision around this issue. This approach is based on a graduate capital model which provides a broader, more holistic understanding of graduate employability. This approach also enables us to work through the challenges of facilitating graduates' transitions and early career management. Many of the dominant HElevel approaches have tended to depict employability as the acquisition and transfer of additional 'key skills' and 'attributes' which can be formally acquired in HE. These have helped promote ways of thinking about graduate skill development, but have also been criticised for being somewhat descriptive and for not capturing the relationship between skills and future employability (Mason et al. 2009; Holmes, 2013; Hinchliffe \& Jolly, 20 II).The graduate capital model provides a firmer context to graduates' educational and wider life experiences, as well as the changing graduate labour market they are entering.

Capitals are conceived here as key resources that confer benefits and advantages onto individuals, enabling them to be more equipped and ready to negotiate the challenges of entering the labour market. The concept of capital, in particular cultural capital, is mainly associated with the work of Bourdieu (1986) who conceived capitals as socially and culturallyderived assets which help reproduce educational inequalities. Whilst the model takes some inspiration from Bourdieu's theorising, it is not confined this approach and draws also on other scholarship, including approaches to capital which are not referred to in his work. 
The resources constituting each form of capital encompass a range of educational, social, cultural and psycho-social dimensions and are acquired through graduates' formal and informal experiences. They also interact and potentially feed into each other.The main forms of capital which are integral to the model are: human, social, cultural, identity and psychological. Whilst each of these components relate to different properties, they overlap to some degree and their boundaries are fairly fluid. The capital approach essentially posits that the formation and deployment of forms of capital can play a considerable role in shaping graduates' transitional experience and early employment outcomes.

Whilst there are inevitable differences in the extent to which graduates acquire different forms of capital, we believe there is scope for them to be further enriched and utilised in ways that serve graduates during and beyond $\mathrm{HE}$. The model depicts two important dimensions for each form of capital: firstly, the key resources constitutive of each form; and, secondly, how they may be utilised by graduates when entering the job market. The development of forms of capital through and around HE is important, as is knowledge of how these have purchase and can enhance graduates' entry to the labour market.

The capital model presents a new vocabulary around graduate employability which can be eventually integrated into careers education, information and guidance. We also believe there is a wider role amongst graduate employers in understanding and recognising these forms and to be more attuned to how these can be enhanced by graduates in their early career stages. Thus, whilst the enrichment of capital presents some challenges for graduates, there is a shared responsibility amongst all stakeholders to find ways of promoting these in practice. For instance, graduate recruiters are also in a strong position to harness forms of capital against organisational demands, as well as looking more holistically at graduates' profiles beyond basic check-lists of core 'attributes' and purported skill-sets. Unlike many dominant approaches to employability, this approach also emphasises the processual nature of graduates' interactions and engagement with the labour market, including the role of significant others (see also Holmes, 2013)
This article provides an overview of the different forms of capital within the model and illustrates their core components and impacts. The final part of the article points towards the practical applications of the model and how practitioners can work with its various components.

\section{Human capital: technical knowledge, hard skills and career-building}

Human capital is the hardest form of capitals that graduates are likely to have acquired. It is built around graduates' level of knowledge and skills, acquired through their formal educational experiences and beyond and is formalised through educational qualifications. Human capital is the closest to skills approach, both in relation to specific occupational domains and more generally. Human capital is strongly associated with the work of economist Gary Becker (1993) who conceived education as a form of investment from which individuals accrue clear returns in the labour market. According to Becker's theory of human capital, this investment entails the enrichment of economically-valuable and productive forms of knowledge and skills which individuals effectively own and draw upon for personal gain. For some graduates, subject-specific knowledge is a strong component of their employability if there are close synergies between curricula content and future occupational task domains. If target employment necessitates the matching of subject knowledge to job demands, human capital will be very foundational to graduates' outcomes.

Human capital can be broken down to two main dimensions. The first is 'hard' skills which are acquired through formal educational learning and the formation of technical, subject-specific and occupational knowledge. For some graduates, subjectspecific knowledge is a strong component of their employability if there are close synergies between curricula content and future occupational task domains. If target employment requires the matching of subject knowledge to job demands, human capital will be foundational to graduates' outcomes. However, even in specialist fields this is often insufficient and 
is clearly less applicable for graduates from more generalist disciplines, for who a degree subject is a threshold qualification.

The second refers to softer forms of human capital which can be couched in terms of graduates' skills and abilities in navigating the labour market. This relates to the 'career-building' skills outlined by Bridgstock (2009) which have a significant bearing on the ways graduates negotiate access to work. These are based on types of knowledge (and related awareness) of not just employment-specific requirements but also wider labour market knowledge. Relevant careerrelated skills include familiarity with one's target labour market (including trends, data, skills demand) and knowing how to apply for and access work (including CV development and entry requirement), as well opportunity awareness and exploitation.

Overall, the significance of human capital lies in the application of both formally-acquired ('hard') skills and technical knowledge, as well as more fluid careerrelevant skills. The need to firmly and contextually-align these to specific job markets is therefore important.

\section{Social capital: networks, bonding and social relationships}

Social capital is defined as the sum of relationships and networks that help mobilise graduates' existing human capital and bring them closer to the labour market and its opportunity structures. It is through the enhancement of social capital that graduates can gain better access to opportunities and understandings of potential job market openings. Social capital is essentially the sum of graduates' social relations which enhances their knowledge of, and access to, target employment. The social relations graduates are able to form before, during and beyond university help generate greater information and knowledge about employment and related opportunities. Prominent scholars associated to this concept (see Coleman, 1988; Granovetter, 1985) have highlighted the significance of bonding and bridging activities between education and work settings. This essentially refers to interactions and relationship formations between individuals and an external group that bring an individual closer to members in that group, including its main gate-keepers.

The concept of 'weak ties' (Granovetter, 1985) is also relevant and constitutes the relatively thin spread of social contacts and connections individuals acquire to help broker trust and gain information and insider knowledge. Whilst in some senses 'strong ties' (e.g. family members) can facilitate immediate access to employment openings, weak ties based on wider associations, networks and newly formed relationships can be also be very gainful. For many graduates this may be fairly emergent, based newly formed relationship with target employers. This can nonetheless be a significant first step towards establishing stronger ties and insider knowledge about job opportunities, as well as knowledge formation about target employment and how best to tailor their profiles.

The key to social capital development is therefore developing appropriate social relations and ties with significant others. This not only helps graduates become known by employers but also strengthens their knowledge and confidence, in turn facilitating access to employment.

\section{Cultural capital: cultural knowledge and confidence}

Whilst a broad concept, we refer to cultural capital as the formation of culturally-valued knowledge, dispositions and behaviours that are aligned to the workplaces that graduates seek to enter. Its strength lies in the ways in which graduates are able to acquire, and also transfer, appropriate cultural, interpersonal and symbolical qualities that signal the alignment of the graduate to a target organisation. One of the issues facing graduates is the declining cultural currency of degree qualifications in mass higher education. Graduates now have to do more to signify the value of their credentials and not just their formal ones. At one level, there is further symbolic value and 'distinction' to be derived from wider sets of achievements and experiences which help differentiate them from others. This is particularly so when these signal wider skills and dispositions which may be valued in specific organisational contexts. It is therefore important 
for graduates to cultivate cultural knowledge and awareness, including the rules of engagement and modes of behaviour within target organisations.

The other key component to cultural capital formation is cultivation of the appropriate embodied capital in the form of behaviours, dispositions and interpersonal qualities that signal their desirability and likely 'social fit' within organisations. Embodied capital conveys behavioural qualities that can present graduates in an advantageous light, particularly in organizational contexts where these come to the fore (i.e. dealing with customers, negotiating, presenting ideas). The closer this is referenced against the context in which it will be deployed and practiced, the greater is likely to be its value. This clearly represents challenges for some graduates, particularly those with less formally-derived cultural capital, for example those first-generation or lower SeS students (see Burke, 2015 and Bathmaker et al. 2013). Yet finding ways of enriching this is part of the challenge for practitioners (see later discussion).

\section{Identity capital: self-concept and personal narratives}

Identity is a significant, albeit fairly personal, form of capital. Identity capital refers principally to psychosocial aspects of a graduates' biography and lived experiences and the extent to which an individual invests in, and defined themselves, in relation to their future employment. The self-perceptions and selfconcepts graduates form around future work can provide a significant frame through which they may be able to channel their experiences and profiles and align theses to the types of employment they are interested in. The relative strength of a graduate's emerging career identity can have a significant impact on how they approach future careers and align their aspirations towards targeted job areas. This partly feeds into graduates' goal-setting capacities and strategies for managing their early experience in the labour market. The establishment and maintenance of emerging career identities is important as this may enable graduates to reflect upon and think through their profile and how this aligns to anticipated future careers. Previous research on student orientations (Tomlinson, 2007) indicates that those whose projected future selves are very much bound up in careers had developed a stronger level of identity capital.

The importance of identity has been demonstrated in a range of research (Hinchliffe and Jolly, 20 I I; Holmes, 20I 3; 20I5; Jackson, 2016).A further significant component to identity capital is also the extent to which graduates can package and present a personal narrative that captures what they are about as individuals. This may be via traditional means such as CV building or via online profile building such as Linkedln or through portfolio creation. Graduates' marketability is increasingly based on the extent to which they can present a compelling employability narrative that conveys their identities. Holmes (2013) has referred to this has the active 'warranting' of an emerging identity, that has to be understood and approved by employers. Jackson (2016) has highlighted the significance of forming a 'pre-professional identity' which is partly derived from students' formal involvement in work-related learning that promotes emergent professional identities and related dispositions. This is also developed in the wider learning communities of higher education, including extra curricula activities and other forms of employer engagement.

In summary, identity capital is significant resource as it can strongly influence how graduates think about themselves in relation to future employment, as well as understand and articulate an employability narrative that captures what they are about and wish to become.

\section{Psychological capital: resilience and adaptability}

The enhancement of a graduate's psychological capital is also an important element in their relationships with the job market. Psychological capital is broadly defined as the capacity for individuals to adapt to challenging personal and job market circumstances and establish a relatively high locus of self-control and persistence. This involves the maintenance of a relatively positive, proactive and resourceful mind-set in challenging environments and the ability to sustain career goals. Stronger levels of psychological capital can equip 
(2) graduates better for the transition to employment by enhancing their self-perceived employability, promoting more proactive and engaged job search pursuits and beneficial coping strategies.

Two key areas are significant to this capital form. The first is self-efficacy which is based on the confidence individuals have to approach and negotiate a task successfully and the positive level of self-attribution over the capacity to succeed. This is clearly important in terms of graduates' self-perceived ability to accomplish career goals but also the capacity to withstand adverse conditions.

The second concerns graduates' level of career resilience which may also depend on the extent to which they can endure and withstand on-going pressures and disruptions in the initial stages of their careers in a potentially uncertain and volatile climate. Stronger resilience enables graduates to adapt to challenging labour market situations, including periods of unemployment and under-employment. A related theme is adaptability in terms of developing strategies that expand the scope of employment opportunity and respond to a changing job context (Savickas \& Porfeli, 2012). As these authors and others have shown, higher overall levels of career adaptability can enable individuals to more readily re-orientate goals and make more proactive decisions when encountering destabilising job market experiences.

Psychological capital is potentially significant for helping graduates more proactively adapt to the challenges of a changing and fluid professional labour market.

\section{Figure 1. Graduate capital model}

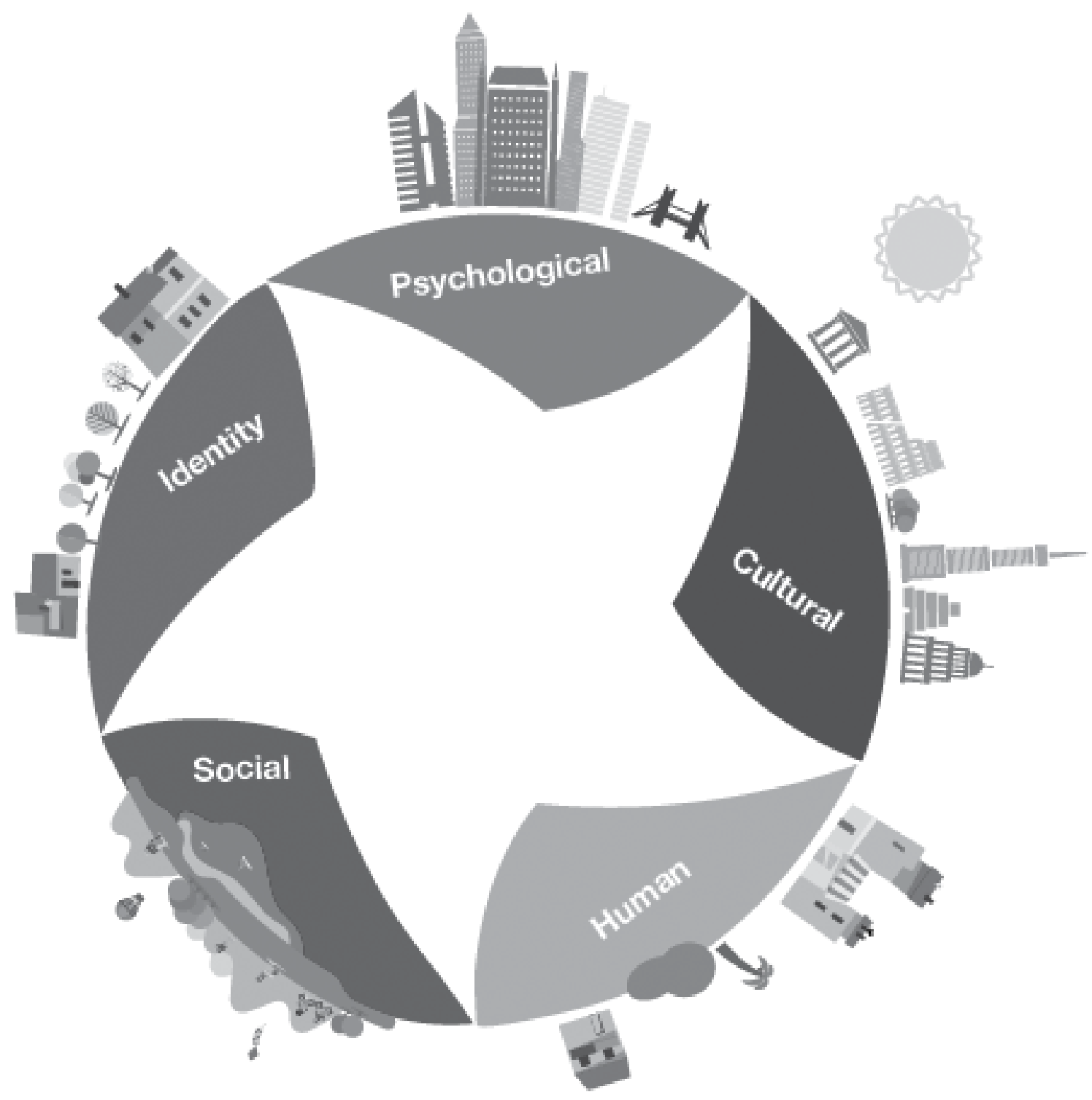




\section{Practical implications of the graduate capital approach}

Working with any employability model presents both opportunities and challenges in finding practical ways forward. Moreover, given the multiple pressures facing current students, there is clearly a need to think proactively around the affordances of the higher education experience and what universities can do for students who may feel less equipped in making the post-university transition. There are a number of overlapping issues in the current model and these principally concern:

- The importance of students and graduates being able to access and articulate formal skills and experiences and present these as meaningfully applicable to target employment;

- The importance of students fully capitalising upon the multi-faceted offerings of the university experience. This includes building experiences and understanding and articulating their significance. The role of work experience is significant and clearly cuts across all the main forms of capital;

- The importance of students thinking proactively about themselves as a future employee and engaging in early career formation, either formally or more ideationally;

- The need for students to be anticipative of likely transitional and early career challenges and hurdles and to start working through strategies to negotiate these;

- The need for students to begin the process of employability development and emerging career formation fairly early into their higher education.

The distinction between the 'possession' of any formal technical or generic knowledge and skills and their active exemplification and application has been highlighted by various scholars in the field (Holmes, 20I3;Tymon, 20I3). Any skill or competence that graduates have acquired needs to be demonstrated, or at least convincingly articulated and given a meaningful context, so that employers are confident that these are aligned to their organisation. This also extends to the types of claims graduates may make about what type of person they currently are and wish to become.

Course leaders need to work in partnership with careers practitioners to ensure that formal curricula are able to emphasise links with related industries. Careers services may be well placed to provide current and relevant links with employers. Furthermore, course teams and careers practitioners need to work together to enable students to be fully aware of and showcase their skills. This might entail encouraging students to be familiar with labour market trends, skills demands and specific professional requirements via formally assessed curriculum interventions.

In thinking about social capital and network formation, there are a number of ways forward, particularly in relation to encouraging graduates' social relationship development through early forms of employer engagement and interaction. These enable better bridging between higher education and graduates' employment.

Students can be encouraged from early stages to make themselves known, or at least visible, to a range of employers. One is through direct contact with employers in ways that facilitate some level of reciprocal knowledge between an employer and graduate. Direct employer engagement through career fairs, employer visits on campus and online profile building (e.g. Linkedln) enable students to develop early bridging and generate better understanding of what a particular employer represents and can potentially offer. An even more direct way is through actual work experience which not only provides direct insider knowledge of the workings of a job and industry, but also a stronger sense as to how to break into it and better tailor their profile. Careers services can play an important role via the creation of short internships, volunteering roles and consultancy projects; particularly in providing a stepping stone for those students who lack social capital.

In terms of the enhancing students' existing cultural capital there is also scope here for developing ways of enhancing students' cultural confidence. One of the key issues highlighted in related 
research is the importance of developing students' cultural understanding and knowledge of targeted organisations, including how it aligned with their own profiles. The latter involves awareness of cultural practices and orientations as well as values and behavioural mores. This in turn can expand students' horizons and potentially unfreeze (mis) perceptions about cultural fit. Some of the work on widening participation points towards ways forward in strengthening students' cultural confidence towards environments in which they are less familiar. Yet it may be the case that employer engagement in some institutions can go some way towards graduates becoming more aware of, and presenting more effectively, wider life and employment experiences in advantageous ways. Similarly, coaching and mentoring offers a potentially strong way forward in helping build graduate capital with employers being trained to enable students to reflect upon, identify and prioritise gaps in their capitals.

There is also scope for practitioners to help students build their existing identity and psychological capital. One of the key challenges is helping graduates to lay claim to the kinds of emergent identities they are forming around future employment and also to help gain social recognition of this. This clearly extends to helping students to present evidence of experiences or performance that capture important aspect of themselves as individuals. In this regard, the $\mathrm{CV}$ becomes a potentially potent medium through which individuals can capture an emerging employability narrative through their accounts of their employment, and related autobiographical, experiences. The accumulation of work-related achievements and experiences in turn become markers of potential organisational value. Practitioners can help students harness their achievements and experiences, including extra curricula activities, so that this best captures emerging employability narrative and provide a competitive advantage.

Whilst it is not always easy to directly enhance a student's career adaptability and resilience, practitioners are nonetheless in a good position to highlight their significance in managing the postuniversity transition. Their role can be to help manage expectations and raise awareness of the importance of resilience in the face of potential job market adversity.
Related to this is encouraging students to develop contingency plans and measures if their initial job outcomes are not favourable.

Taken together, we see this approach as an effective way forward - one which can help both practitioners and graduates develop key resources that enable them to be more ready to meet the challenges of a current graduate labour market. Whilst the model is based on an extensive literature and current thinking in the field, there is further work to be done to apply it and explore its efficacy. In support of this, a bank of learning outcomes have been developed by colleagues within the Careers and Employability Service at the University of Southampton. These are being used to support the development of three careers education modules, all of which will form detailed case studies next year. Colleagues have also developed a selfdiagnostic test, 'The Career Readiness Test', which will enable students to self-assess their progress against the model and identify action going forward. The views of employers are being sought via a Learning Gain project (which the authors at this institution are co-investigators on with a range of other HEls). In the early stages of this research, the employers who have been interviewed have already indicated the importance of these forms of capital and how they are reflected in the assessment process.

\section{References}

Bathmaker, A.M., Ingram, N. \& Waller, R. 2013. Higher Education, Social Class and the Mobilisation of capitals: recognising and playing the game, British Journal of Sociology of Education, 34 (5/6): 723-743.

Becker, G. (1993) Human Capital: theoretical and empirical analysis with special reference to education (3rd Edition), Chicago: University of Chicago Press.

Bourdieu, P. (1986), 'The Forms of Capital', In J. Richardson (Ed.), Handbook for Theory and Research for the Sociology of Education, Greenwood, Westport, CT, PP $24 \mid-255$ 
Brigstock, R. (2009) The graduate attributes we've overlooked: enhancing graduate employability through career management skills, Higher Education Research and Development 28(I): 3I-44.

Burke, C. (2015) Culture, Capital and Graduate Futures: degrees of class, London: Routledge.

Coleman, J.S. (1988) Social capital in the creation of human capital, American Journal of Sociology, 94: 95-120.

Department for Business, Innovation and Skills (2016) Success as a Knowledge Economy: teaching excellence, social mobility and student choice, London: HMSO.

Granovetter, M. (1985) Economic Action and Social Structure: the problem of embeddedness, American Journal of Sociology, 9 I (3): 48I-5I 0.

Hinchliffe, G. and Jolly,A. (20I I) Graduate Identity and Employability, British Educational Research Journal, 37(4): 563-584.

Holmes, L. (2013) Competing Perspectives on Graduate Employability: possession, position or process? Studies in Higher Education, 38, (4): 538-554.

Holmes, L. (2015) Becoming a graduate: the warranting of an emergent identity, Education + training, 57 (2): 219-238.

Jackson, D. (2016) Re-conceptualising graduate employability: the importance of pre-professional identity, Higher Education Research \& Development (online)

Mason, G.,Williams, G and Cramner, S. (2009) Employability skills initiatives in higher education: what effects do they have on graduate labour market outcomes? Education Economics, 17(1): 1-30.

Savickas, M.L. \& Porfeli, E.J. (2012) Career AdaptAbilities Scale: Construction, reliability and measurement equivalence across 13 countries, Journal of Vocational Behaviour, 80, 66I -673.

Tomlinson, M. (2007) Graduate employability and student attitudes and orientations to the labour market, Journal of Education and Work, 20 (4): 285-304.

Tymon,A. (2013) The student perspective on employability, Studies in Higher Education, 38, 6, 84I-856.

\section{For correspondence}

Michael Tomlinson

M.B.Tomlinson@soton.ac.uk 